\title{
Designing a Single-Stage Inverter for Photovoltaic System Application
}

\author{
M. T. Tsai, C. L. Chu, C. M. Mi, J. Y. Lin, and Y. C. Hsueh \\ Southern Taiwan University of Science and Technology, No. 1, Nan-Tai Street, Yungkang District, Tainan City 710, Taiwan \\ Correspondence should be addressed to M. T. Tsai; mttsai@mail.stust.edu.tw
}

Received 12 September 2013; Accepted 8 October 2013

Academic Editor: Teen-Hang Meen

Copyright ( 2013 M. T. Tsai et al. This is an open access article distributed under the Creative Commons Attribution License, which permits unrestricted use, distribution, and reproduction in any medium, provided the original work is properly cited.

\begin{abstract}
This paper focuses on a full-bridge high-frequency isolated inverter which is proposed for distributed photovoltaic power supply application. The researched system consists of a full-bridge high-frequency DC/DC converter with the proposed symmetric phaseshift modulation algorithm to achieve the ZVS switching function and a line frequency unfolding bridge. It replaces the traditional two stages of independent control algorithms with a one-stage control to obtain high conversion efficiency. A TMS 320F2812 digital signal processor-based control technique is used to achieve the desired algorithm function for the grid-connected photovoltaic power system application. The researched system can have two operating methods depending on the applied situation. Finally, a prototype of $300 \mathrm{~W}$ with the maximum power point function is settled to verify the proposed idea.
\end{abstract}

\section{Introduction}

Recently, renewable energy, such as wind power and photovoltaic cell (PV), feeding the distributed power systems, has been increased and more visibile. For PV applications, since the conversion becomes more and more efficient due to the different existing conversion technologies and the decreasing price of the PV modules, it has become suitable for smallscale residential applications with a range below $1 \mathrm{~kW}$ [16]. There are many existing power inverter topologies for interfacing PV modules to the used terminal. Generally, a PV power system can be divided into stand-alone system and grid-connected system depending on whether it is parallel with the utility or not. For the stand-alone system, it usually needs batteries to give a supplement to the insufficient photovoltaic power. Stand-alone system is mainly used in the place without utility source or sparsely populated areas where the utility cannot supply energy with low cost. Grid-connected system is mainly used in the area where the utility can be served. Inverters connected to the grid involve two major functions, one is to ensure that the PV is operated with the maximum power point tracking (MPPT) and the other is to inject a sinusoidal current into the grid [7-11].
Development of grid-connected photovoltaic power supply system is divided into two categories, including centralized converter type and microconverter type [1-5]. The former uses multiple photovoltaic modules for string and/or parallel combination to concentrate the utility; such a framework is usually to adopt a stable DC bus design and it uses a large capacity of electrolyte capacitor to obtain a stable DC voltage; its advantages are more flexible than converter design, but with a worse operation performance for each module, while the latter, oppositely usually uses one or few photovoltaic modules to the utility, and the pulsating DC bus design and a small volume electrolyte capacitor are adopted. Thus, photovoltaic modules can have a better running performance. However, each team of photovoltaic modules requires a special convertor to transfer the energy to the electricity.

A single-stage high-frequency converter topology for decentralized PV systems has been presented in this paper for small-scale residential applications. In contrast to the classic converter topologies the proposed scheme presents a high power density. The researched system consisted of a fullbridge high-frequency DC/DC converter with the proposed symmetric phase-shift modulation algorithm to achieve the ZVS switching function and a DC/AC inverter which can 


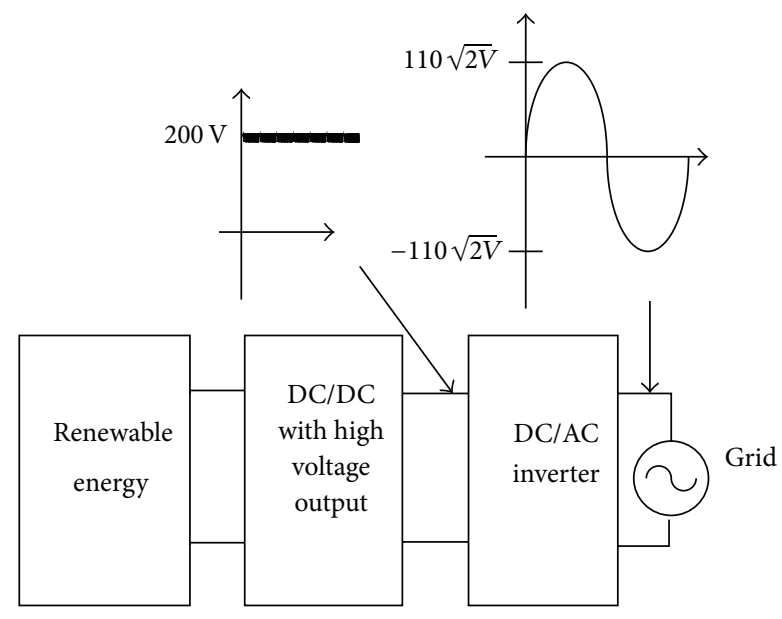

(a)

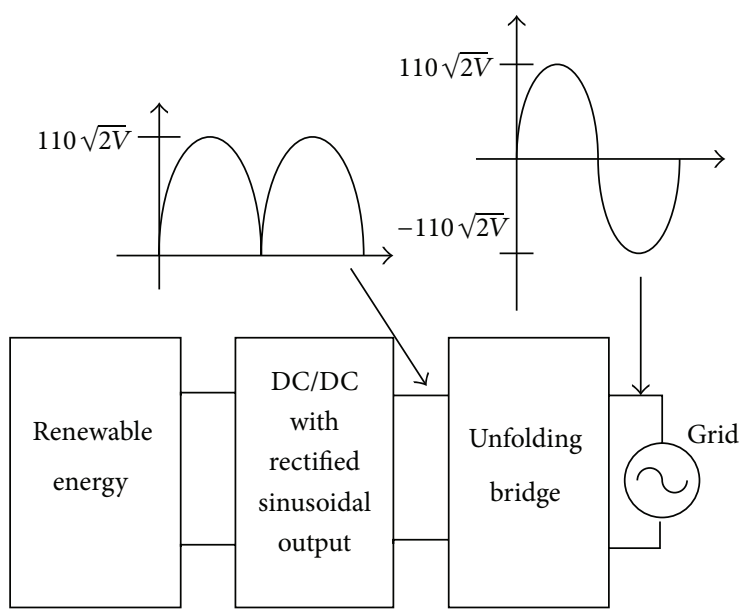

(b)

Figure 1: (a) Two-stage control-based PV system. (b) Single-stage control-based PV system.

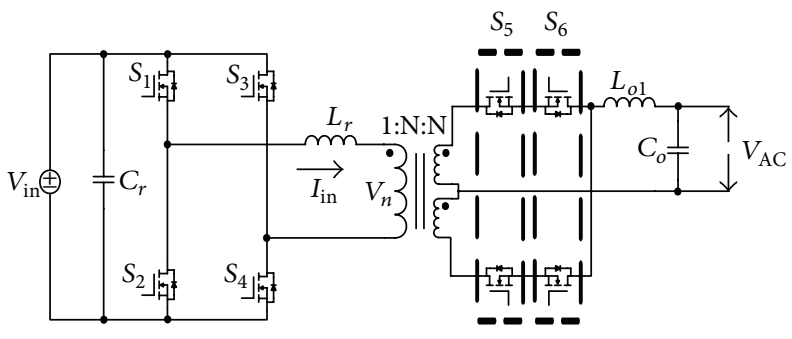

(a)

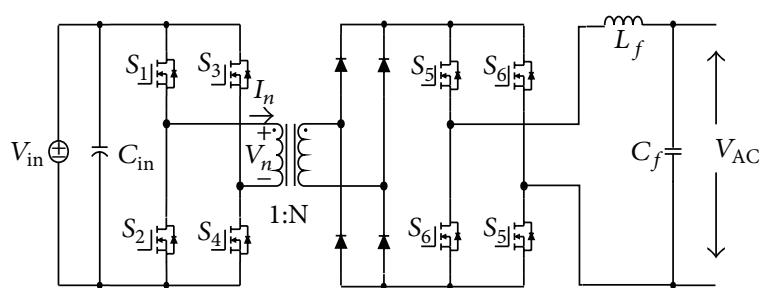

(b)

Figure 2: (a) The proposed single-stage control-based PV system architecture 1. (b) The proposed single-stage control-based PV systemarchitecture 2 .

have two operating methods depending on the load characteristic. With the proposed control algorithm, it meets the requirement of a high efficiency conversion.

\section{System Structure}

PV power system is roughly divided into two major categories isolated and nonisolated. This study was to investigate the design of high-frequency isolated structure. For such an architecture, it is basically divided into two control designs depending on the availability large electrolyte capacitor, and can be described as follows.

2.1. Comparison of Two-Stage and Single-Stage Control-Based $P V$ System. Two-Stage control based PV system basically consists of a high-frequency DC/DC stage whose output is connected to a stiff DC bus voltage which is with large electrolyte capacitors. Then the second DC/AC stage operated in sinusoidal pulse-width modulation switching transfers the energy to the utility. It can be shown in Figure 1(a). In contrast to this, the single-stage control based PV system basically consists of a high-frequency DC/DC stage whose output connected to a pulsating DC bus voltage which is with no electrolyte capacitors. Then an unfolding full-bridge inverter switched in $60 \mathrm{~Hz}$ transfers the energy to the utility. It can be shown in Figure 1(b).

2.2. Single-Stage Control Based PV System. The proposed single-stage control based PV system can be implemented in two ways as shown in Figures 2(a) and 2(b). These two architectures have common characteristic of using pulselink DC-AC convertor [6]; therefore, a pulsating waveform presented in its DC output side. The difference between them is that the former's output stage can do the PWM switching in order to implement the nonunit power factor current, while the latter does not have this ability. When parallel to the utility, the control responsibility of both architectures in no change at the first stage, while the second stage is responsible only for low frequency (e.g., $60 \mathrm{~Hz}$ ) switching to lower the switching losses. Under this situation, feeding a nonunit power current into the main will cause a distorted current waveform, and the distorted current can be solved by a properly PWM switching algorithm for Figure 2(a) but cannot be fitted for Figure 2(b).

This study is focused on a single-stage control based PV system shown in Figure 2, and a symmetric phaseshift control algorithm is adopted to replace the traditional SPWM switching algorithm so as to achieve the zero-voltage 


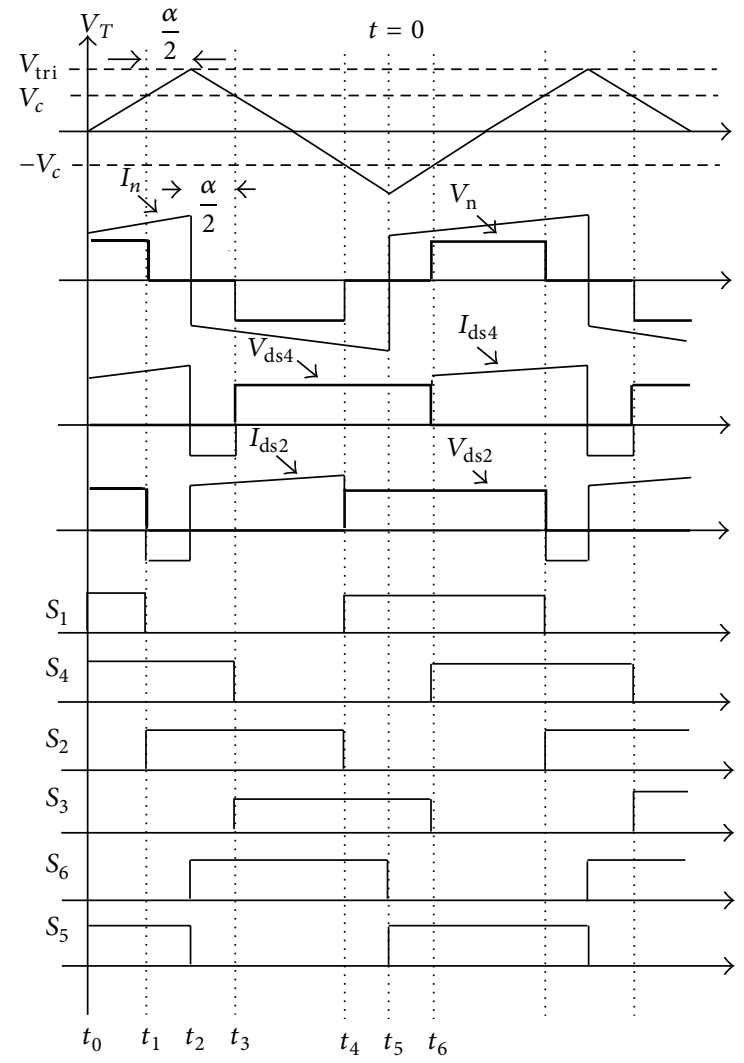

FIgURE 3: The conducting status of Figure 2(a) in stand-alone operation.

switching function. Also, two different switching modes will be introduced to cope with the unity power factor current demand or non-unit power current demand.

\section{Symmetric Phase-Shift Control Algorithm}

Conventional full-bridge phase-shift converter uses the parasitic capacitance on the switching elements and the leakage inductance existed in the high-frequency transformer to get the zero voltage switching effect. The advantages include reduced switching loss and the switch stress. However, it is suitable for DC/DC converter and cannot satisfy the sine wave output requirement. In response to the requirement achieved by single-stage control, this paper proposes a symmetric phase-shift control to fulfill the DC/AC function. The control algorithm is shown as follows.

In the case of Figure 1(a), the modulation function achieved by $S_{1} \sim S_{4}$ before high frequency transformer, denoted as $H_{F}(t)$, can be described in (1), where $\alpha$ is denoted as the desired phase shift angle:

$$
H_{F}(t)= \begin{cases}+V_{\text {in }}, & \frac{\alpha}{2} \leq t \leq \frac{T_{s}}{2}-\frac{\alpha}{2}, \\ -V_{\text {in }}, & \frac{T_{s}}{2}+\frac{\alpha}{2} \leq t \leq T-\frac{\alpha}{2}, \\ 0, & \text { elsewhere. }\end{cases}
$$

Then, the modulation function achieved by $S_{5} \sim S_{6}$ after high frequency transformer, denoted as $H_{B}(t)$, can be described as

$$
H_{B}(t)=\left(\begin{array}{cc}
1 & 0 \leq t \leq \frac{T_{s}}{2} \\
-1 & \frac{T_{s}}{2} \leq t \leq T_{s}
\end{array}\right) .
$$

Thus, the primary voltage $V_{n}$ and the control command $V_{c}$ can be shown as follows:

$$
\begin{gathered}
V_{n}=V_{\text {in }}\left(1-\frac{2 \alpha}{T_{s}}\right), \\
\alpha=0, \quad V_{n}=V_{\text {in }}, \\
\alpha=\frac{T_{s}}{2}, \quad V_{n}=0, \\
\alpha=T_{s}, \quad V_{n}=-V_{\text {in }}, \\
V_{c}=\left(1-\frac{2 \alpha}{T_{s}}\right) .
\end{gathered}
$$

To obtain a sinusoidal output, the command $V_{c(t)}$ should be a $\sin \omega t$ waveform; that is:

$$
V_{c}(t)=V_{c} \sin \omega t
$$

Therefore, the output after $S_{5} \sim S_{6}$ can be expressed as follows:

$$
V_{o}=N V_{\text {in }} \frac{V_{c}}{V_{\text {in }}} \sin \omega t .
$$

3.1. Stand-Alone Operation. In this situation, the PV inverter should be capable of supplying non-unit power factor current drawn by the load; thus only the structure shown in Figure 2(a) can fulfill the requirement, and Figure 3 shows the conducting status in this operation.

3.1.1. Interval $\left(t_{0} \leq t<t_{1}\right)$. In this status, $S_{1}$ and $S_{4}$ are $\mathrm{ON}$; $S_{2}$ and $S_{3}$ are OFF. The transformer primary voltage is equal to the DC input voltage, and input current flows through the transformer primary side and the switches to form a current loop, making the power from the input source through the transformer to the secondary side, and then through the $S_{5}$ to the load. Figure 4(a) shows the energy transfer interval.

3.1.2. Interval $\left(t_{1} \leq t<t_{3}\right)$. As shown in Figure 4(b) in this status, $S_{2}$ and $S_{4}$ are ON; $S_{1}$ and $S_{3}$ are OFF. The energy flows through $S_{2}$ and the transformer primary side to form a flywheel current loop, and the transformer primary voltage $V_{n}$ is in short status. For the transformer secondary, $S_{5}$ is $\mathrm{ON}$ at $t_{1} \leq t<t_{2}$ and $S_{6}$ is $\mathrm{ON}$ at $t_{2} \leq t<t_{3}$.

3.1.3. Interval ( $t_{3} \leq t<t_{4}$ ). In this status, $S_{2}$ and $S_{3}$ are $\mathrm{ON} ; S_{1}$ and $S_{4}$ are OFF. The transformer primary voltage is equal to the negative DC input voltage, and input current flows through the transformer primary side and the switches 


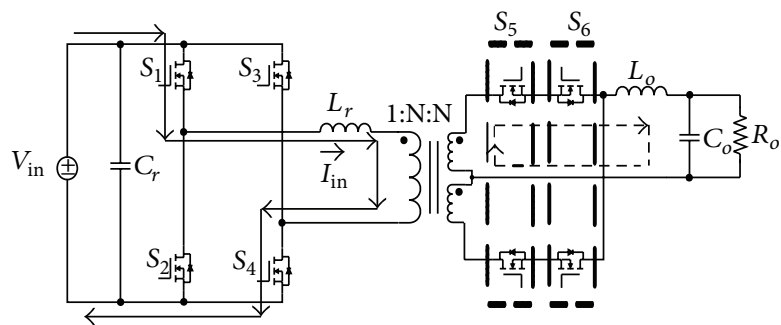

(a)

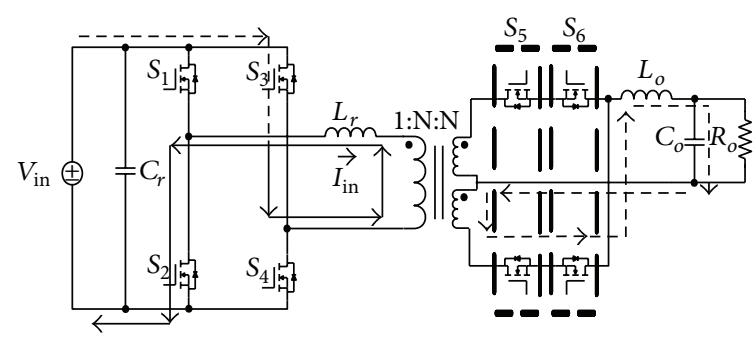

(c)

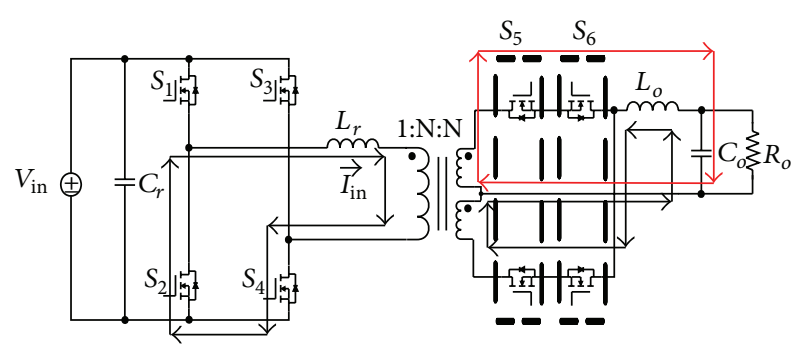

(b)

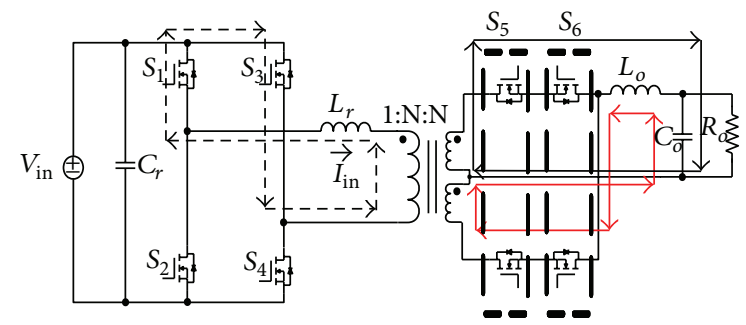

(d)

FIGURE 4: (a) Energy transfer interval I. (b) Energy flywheel interval I. (c) Energy transfer interval II. (d) Energy flywheel interval II.

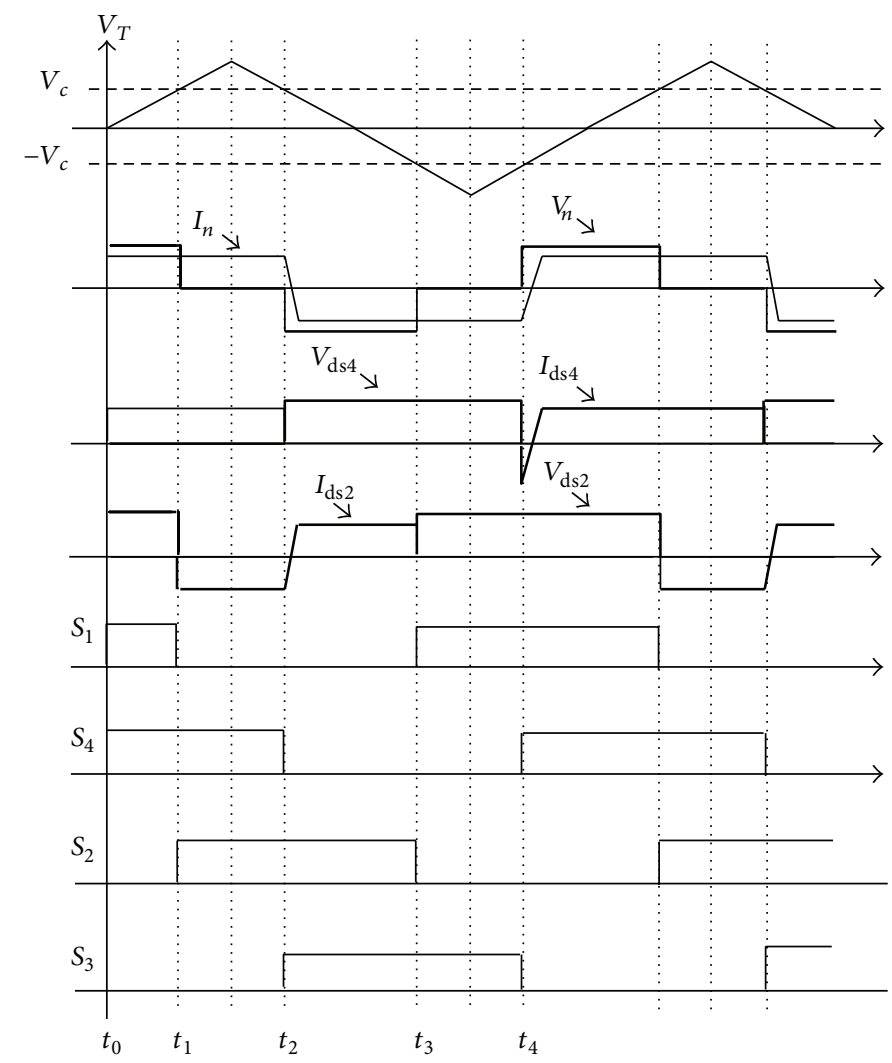

FIGURE 5: The conducting status due to Figure 2(b) structure.

to form a current loop, making the power from the input source through the transformer to the secondary side, and then through the $S_{6}$ to the load. Figure 4(c) shows the energy transfer interval.
3.1.4. Interval $\left(t_{4} \leq t<t_{6}\right)$. As shown in Figure $4(\mathrm{~d})$ in this status, $S_{1}$ and $S_{3}$ are ON; $S_{2}$ and $S_{4}$ are OFF. The energy flows through $S_{1}$ and the transformer primary side to form a flywheel current loop, and the transformer primary voltage 


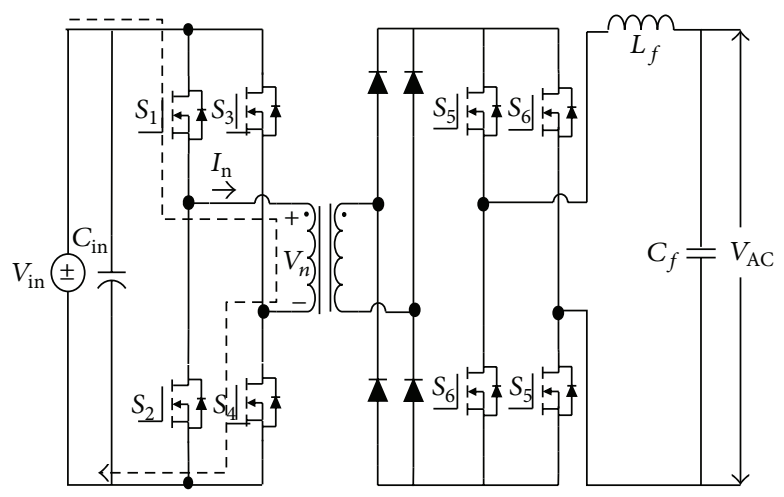

(a)

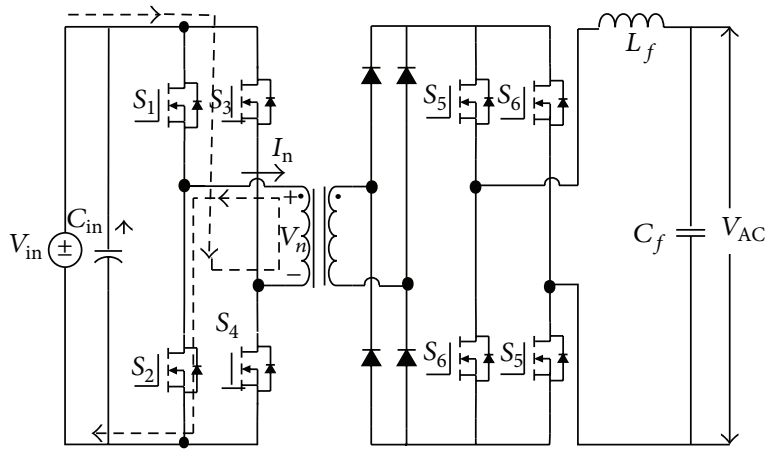

(c)

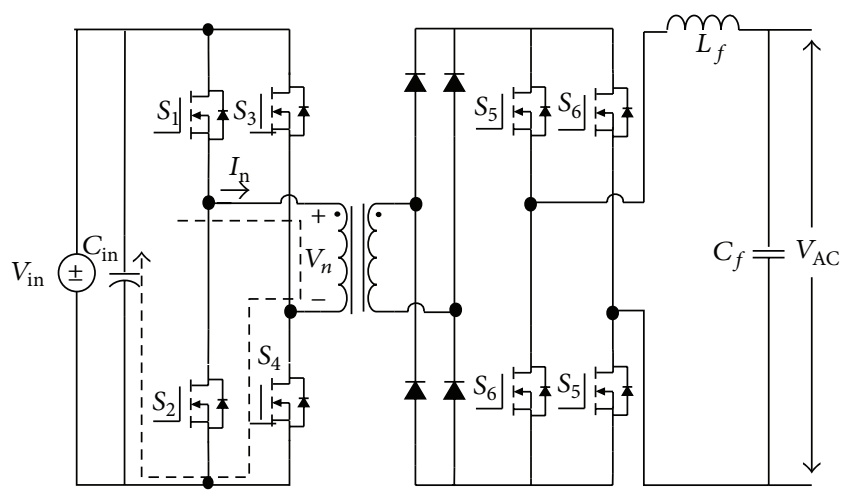

(b)

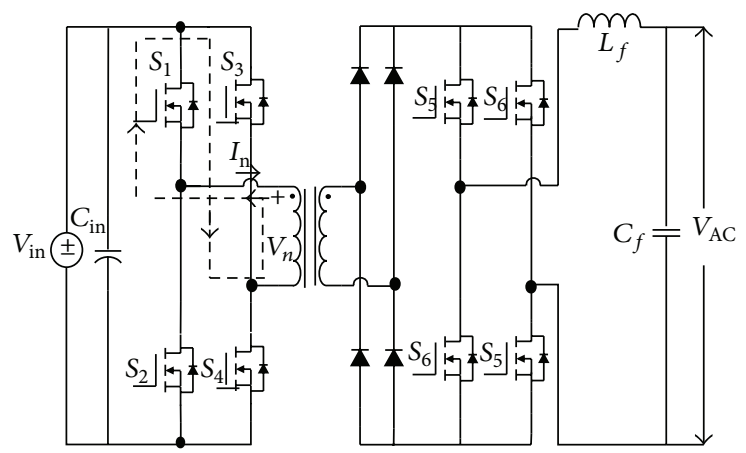

(d)

Figure 6: (a) Energy transfer interval I. (b) Energy flywheel interval I. (c) Energy transfer interval II. (d) Energy flywheel interval II.

$V_{n}$ is in short status. For the transformer secondary, $S_{6}$ is $\mathrm{ON}$ at $t_{4} \leq t<t_{5}$ and $S_{5}$ is $\mathrm{ON}$ at $t_{5} \leq t<t_{6}$.

3.2. Grid-Connected Operation. In this situation, the PV inverter should be capable of supplying unity power factor current to the utility; thus both the structures shown in Figures 2(a) and 2(b) can fulfill the requirement, where the transformer secondary power switches $S_{5}$ and $S_{6}$ used as the unfolding bridge and switching at $60 \mathrm{HZ}$. An example based on Figure 2(b) topology can be shown in Figures 5 and 6, where Figure 5 shows the conducting status in the proposed control algorithm, and Figure 6 shows the four conducting stages.

3.2.1. Interval $\left(t_{0} \leq t<t_{1}\right)$. As shown in Figure 6(a), in this status $S_{1}$ and $S_{4}$ are ON; $S_{2}$ and $S_{3}$ are OFF. The transformer primary voltage is equal to the DC input voltage, and input current flows through the transformer primary side and the switches to form a current loop, making the power from the input source through the transformer to the secondary side, then through the $S_{5}$ or $S_{6}$ to the load dependent on the positive or negative cycle.

3.2.2. Interval ( $t_{1} \leq t<t_{2}$ ). As shown in Figure 6(b), in this status $S_{2}$ and $S_{4}$ are ON; $S_{1}$ and $S_{3}$ are OFF. The energy flows through $S_{2}$ and the transformer primary side to form a flywheel current loop, and the transformer primary voltage $V_{n}$ is in short status.

3.2.3. Interval $\left(t_{2} \leq t<t_{3}\right)$. As shown in Figure 6(c), in this status $S_{2}$ and $S_{3}$ are ON; $S_{2}$ and $S_{4}$ are OFF. The transformer primary voltage is equal to the negative $\mathrm{DC}$ input voltage, and input current flows through the transformer primary side and the switches to form a current loop, making the power from the input source through the transformer to the secondary side, and then through the $S_{5}$ or $S_{6}$ to the load dependent on the positive or negative cycle.

3.2.4. Interval ( $t_{3} \leq t<t_{4}$ ). As shown in Figure 6(d), in this status $S_{1}$ and $S_{3}$ are ON; $S_{2}$ and $S_{4}$ are OFF. The energy flows through $S_{1}$ and the transformer primary side to form a flywheel current loop, and the transformer primary voltage $V_{n}$ is in short status.

3.3. Implementation. A prototype of $300 \mathrm{~W}$ due to Figure 2(b) structure has been settled to verify the proposed idea for stand-alone operation and grid-connected operation. The proposed DSP TMS320F2812 processorbased single-stage control block diagram dependent on the operation condition can be shown in Figures 7(a) and 7 (b). Figure 7(a) shows the control block diagram for the stand-alone operation, and Figure 7 (b) shows the control block diagram for the grid-connected operation. Figure 7(c) 


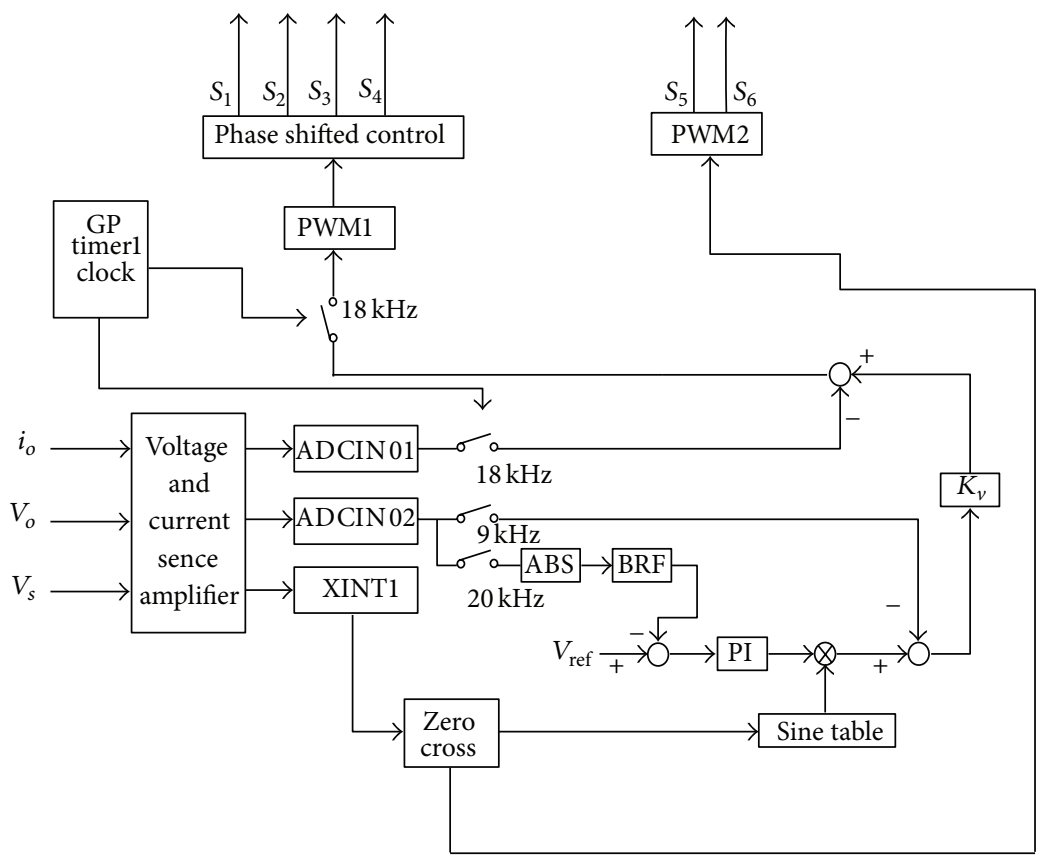

(a)

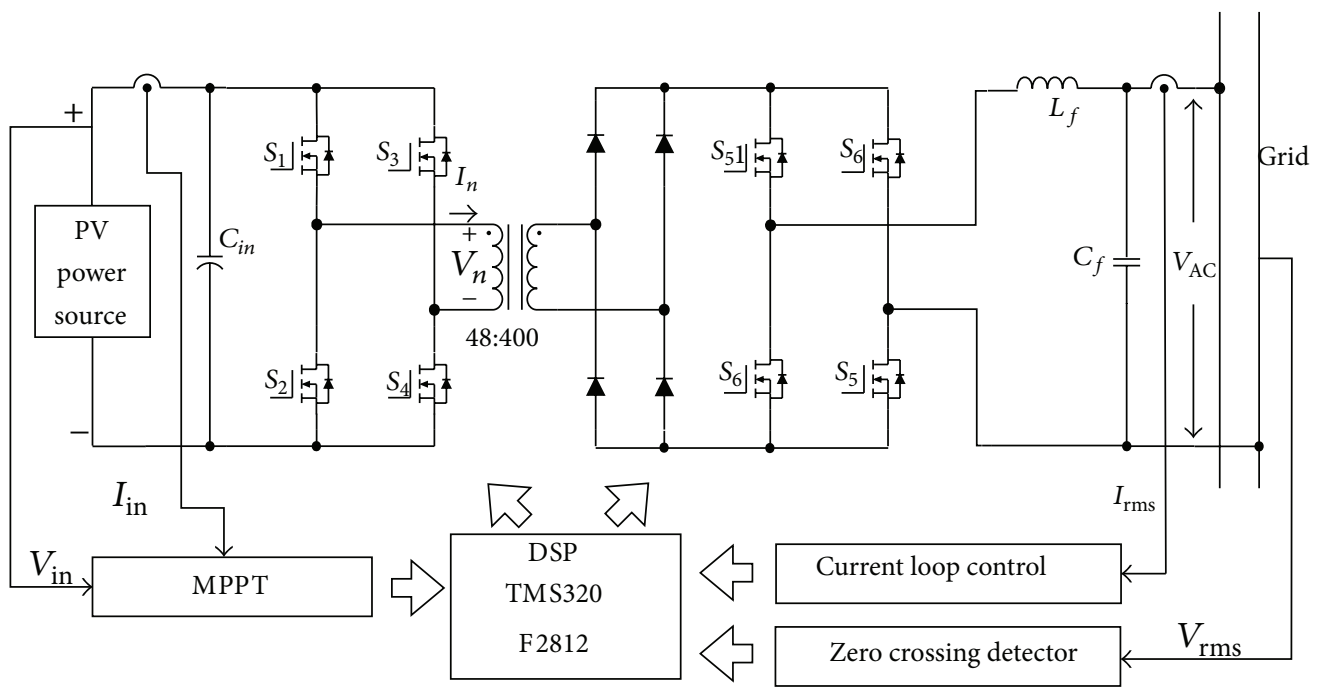

(b)

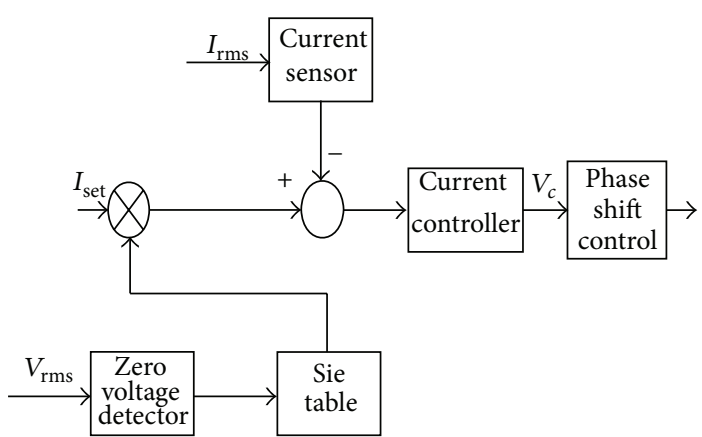

(c)

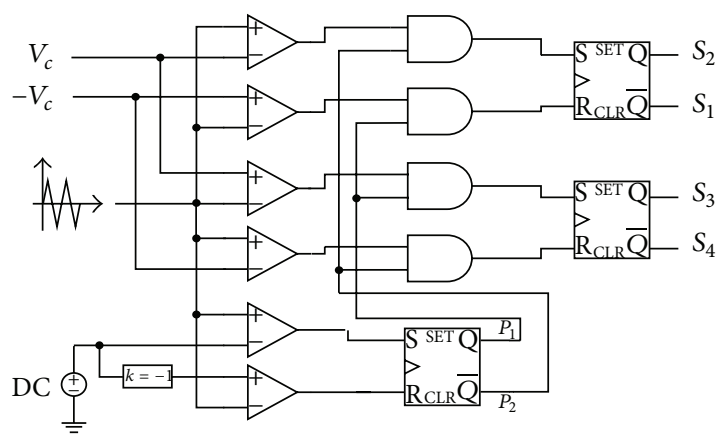

(d)

FIGURE 7: (a) DSP-based control block diagram for the stand-alone operation. (b) DSP-based control block diagram for the grid-connected operation. (c) Current control loop. (d) Modulation strategy used for the grid-connected operation. 


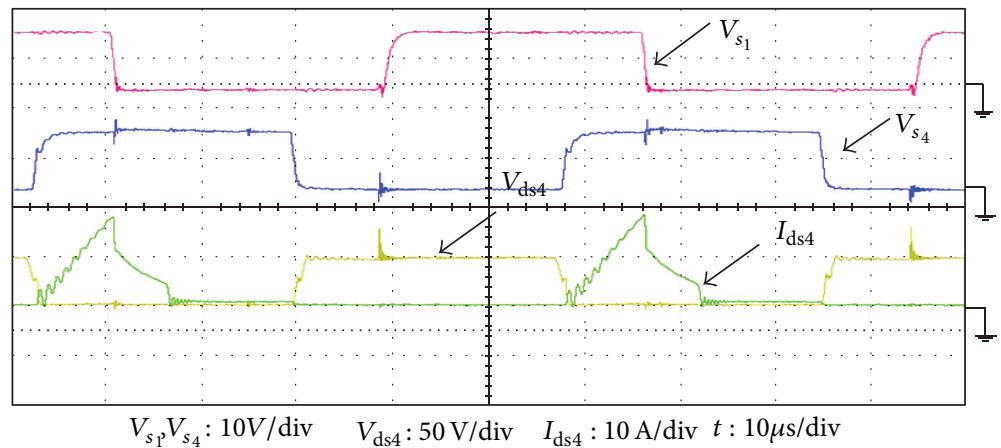

FIgURE 8: The driving signals $V_{s 1}, V_{s 4}$, the corresponding voltage $V_{\mathrm{ds} 4}$, and current $I_{\mathrm{ds} 4}$ of $S_{4}$.

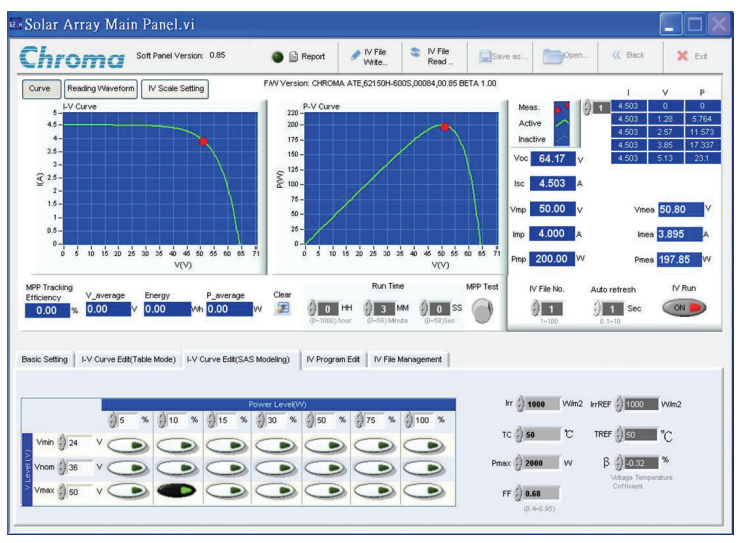

(a)

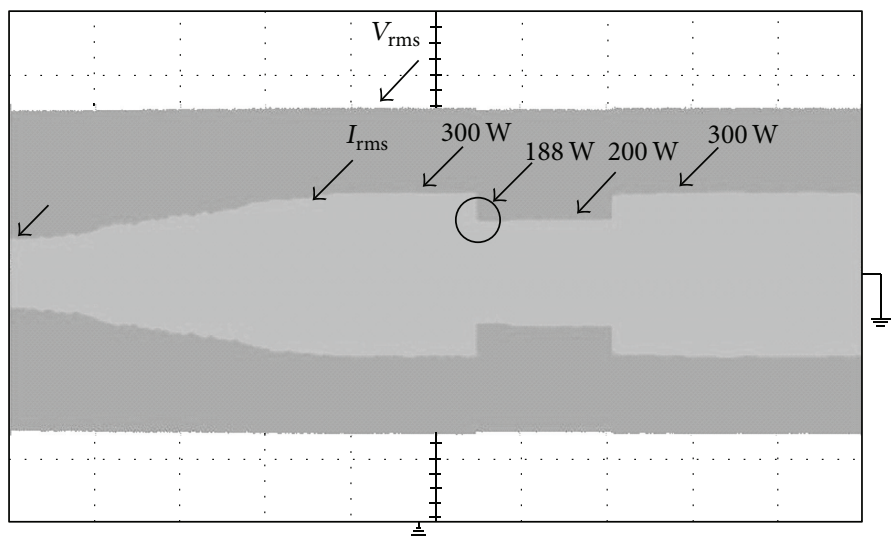

(b)

FIGURE 9: The maximum power point tracking function in the proposed microinverter via a PV emulator manufactured by the Chroma company, (a) the maximum power point operating at $200 \mathrm{~W}$, and (b) the tracking performance due to the PV power change of $300 \mathrm{~W}-$ $200 \mathrm{~W}-300 \mathrm{~W}$.

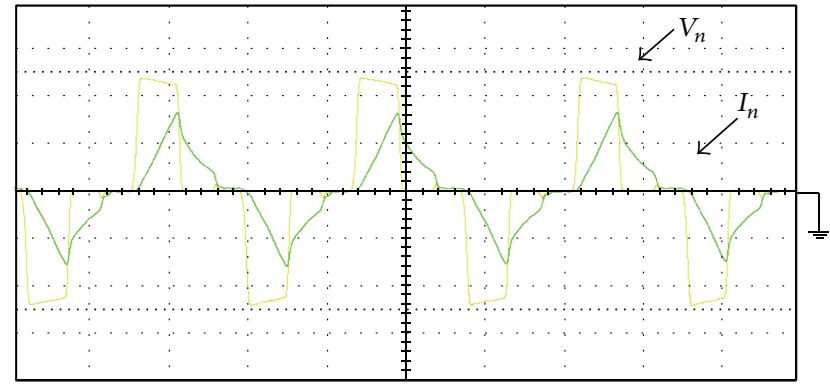

FIGURE 10: The primary input voltage and current of the highfrequency transformer.

shows the current controller, and Figure 7(d) shows the modulation strategy for $S_{1} \sim S_{4}$ used for the grid-connected operation.

\section{Simulation and Experimental Results}

The system parameters used in the prototype are shown in Table 1.

Figure 8 shows the experimental results, including the driving signals of the switching devices, $S_{1}, S_{4}$, and the
TABLE 1: The parameters used in the experimental system.

\begin{tabular}{lc}
\hline$V_{\text {in }}$ & $40 \sim 60 \mathrm{~V}$ \\
$V_{o}$ & $110 V_{\mathrm{AC}}$ \\
$S_{1} \sim S_{6}$ & IXTQ69N30 \\
$L_{f}$ & $220 \mathrm{uF}$ \\
$C_{f}$ & $2.2 \mathrm{uF}$ \\
Switching frequency & $18 \mathrm{kHz}$ \\
Output power & $300 \mathrm{~W}$ \\
\hline
\end{tabular}

corresponding voltage waveform and current waveform of $S_{4}$. It shows that the switches can achieve ZVS function.

Figure 9 shows the maximum power point tracking function in the proposed microinverter via a PV emulator manufactured by the Chroma company. The PV output power is set at $200 \mathrm{~W}$. It shows the proposed microinverter is operated at the maximum power related to the set point.

Figure 10 shows the primary input voltage and current of the high frequency transformer. It shows that no bias current existed there.

Figure 11 shows the inverter output voltage and current in the case of stand-alone situation and the grid-connected 


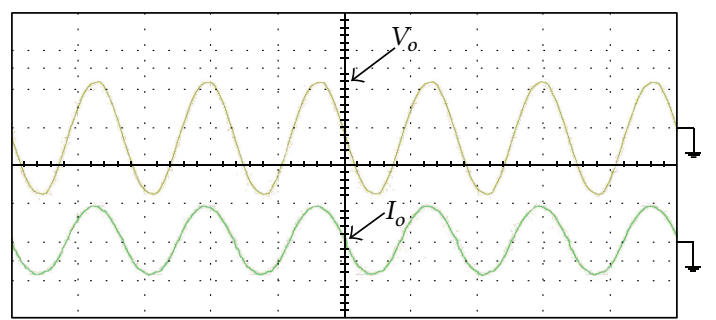

(a)

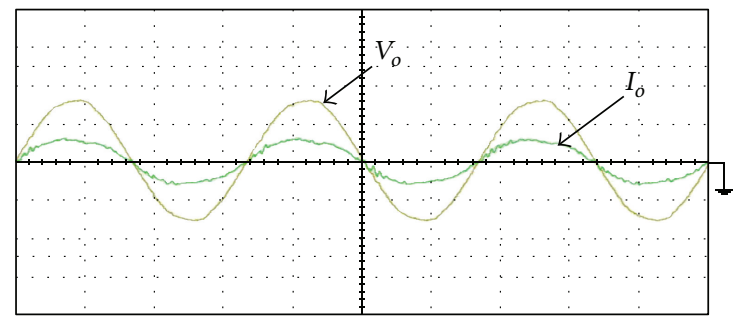

(b)

FIGURE 11: The inverter output voltage and current, (a) the standalone operation, and (b) the grid-connected operation. $V_{0}: 100 \mathrm{~V} / \mathrm{div}$. $I_{0}: 5 \mathrm{~A} /$ div. $t: 2.5 \mathrm{~ms} /$ div.

situation. Figure 11(a) shows the stand-alone operation, and Figure 11(b) shows the grid-connected operation. It shows the proposed micro inverter can achieve the inphase current function due to the current control loop, and with low harmonics. The overall system efficiency is about $90 \%$.

\section{Conclusion}

This paper discusses the steady-state behavior of the singlestage control-based inverter when controlled via a symmetrical phase shift modulation. The single-stage control based algorithm to replace the traditional two-stage control in the micro inverter applications can reduce the system complexity and increase the reliability due to the lack of the electrolytic capacitor. With the use of new symmetrical phase shift control, the ZVS switching performance can be achieved for the proposed micro inverter so as to reduce the switching stress and switching loss and thus improve the inverter's overall efficiency. The theoretical framework is validated by means of computer simulations and experimental results on a $300 \mathrm{~W}$ prototype.

\section{Acknowledgment}

This work has been supported by National Science Council, Taiwan, under research project NSC101-2221-E-218-040.

\section{References}

[1] R.-J. Wai and W.-H. Wang, "Grid-connected photovoltaic generation system," IEEE Transactions on Circuits and Systems I, vol. 55, no. 3, pp. 953-964, 2008.

[2] S. B. Kjaer, J. K. Pedersen, and F. Blaabjerg, "A review of singlephase grid-connected inverters for photovoltaic modules," IEEE
Transactions on Industry Applications, vol. 41, no. 5, pp. 12921306, 2005.

[3] Q. Li and P. Wolfs, "A review of the single phase photovoltaic module integrated converter topologies with three different DC link configurations," IEEE Transactions on Power Electronics, vol. 23, no. 3, pp. 1320-1333, 2008.

[4] N. Kasa, T. Iida, and L. Chen, "Flyback inverter controlled by sensorless current MPPT for photovoltaic power system," IEEE Transactions on Industrial Electronics, vol. 52, no. 4, pp. 11451152, 2005.

[5] T. Shimizu, K. Wada, and N. Nakamura, "Flyback-type singlephase utility interactive inverter with power pulsation decoupling on the DC input for an AC photovoltaic module system," IEEE Transactions on Power Electronics, vol. 21, no. 5, pp. 12641272, 2006.

[6] D. Chen and L. Li, "Novel static inverters with high frequency pulse DC link," IEEE Transactions on Power Electronics, vol. 19, no. 4, pp. 971-978, 2004.

[7] S. Jain and V. Agarwal, "Comparison of the performance of maximum power point tracking schemes applied to singlestage grid-connected photovoltaic systems," IET Electric Power Applications, vol. 1, no. 5, pp. 753-762, 2007.

[8] N. Femia, G. Petrone, G. Spagnuolo, and M. Vitelli, “Optimization of perturb and observe maximum power point tracking method," IEEE Transactions on Power Electronics, vol. 20, no. 4, pp. 963-973, 2005.

[9] A. K. Abdelsalam, A. M. Massoud, S. Ahmed, and P. N. Enjeti, "High-performance adaptive Perturb and observe MPPT technique for photovoltaic-based microgrids," IEEE Transactions on Power Electronics, vol. 26, no. 4, pp. 1010-1021, 2011.

[10] D. Chen and J. Liu, "The uni-polarity phase-shifted controlled voltage mode ac-ac converters with high frequency ac link," IEEE Transactions on Power Electronics, vol. 21, no. 4, pp. 899905, 2006.

[11] A. K. Abbasi and M. W. Mustafa, "Mathematical model and stability analysis of inverter-based distributed generator," Mathematical Problems in Engineering, vol. 2013, Article ID 195038, 7 pages, 2013. 


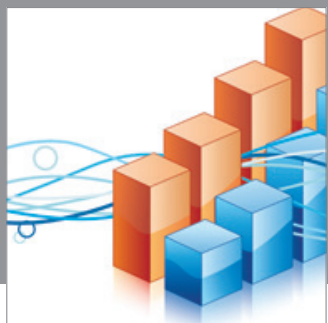

Advances in

Operations Research

mansans

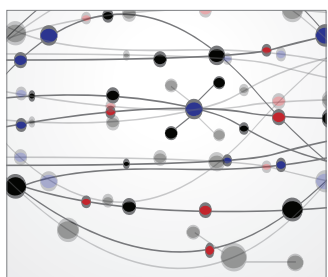

The Scientific World Journal
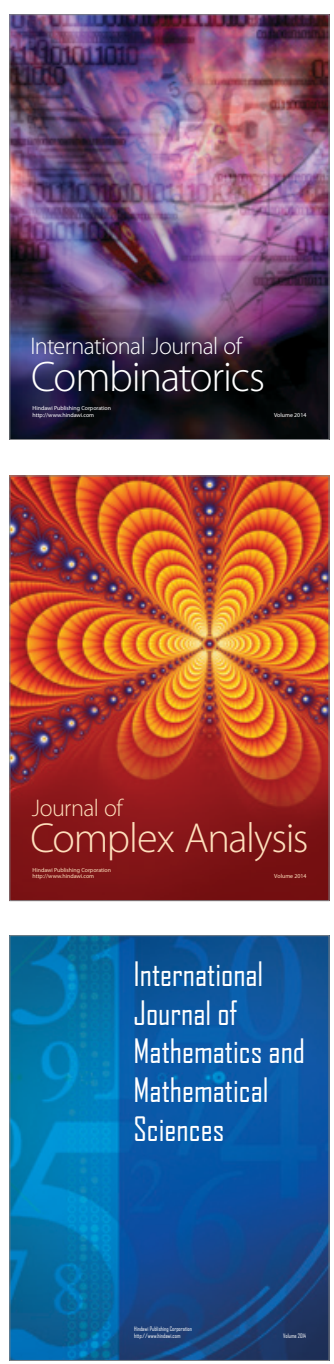
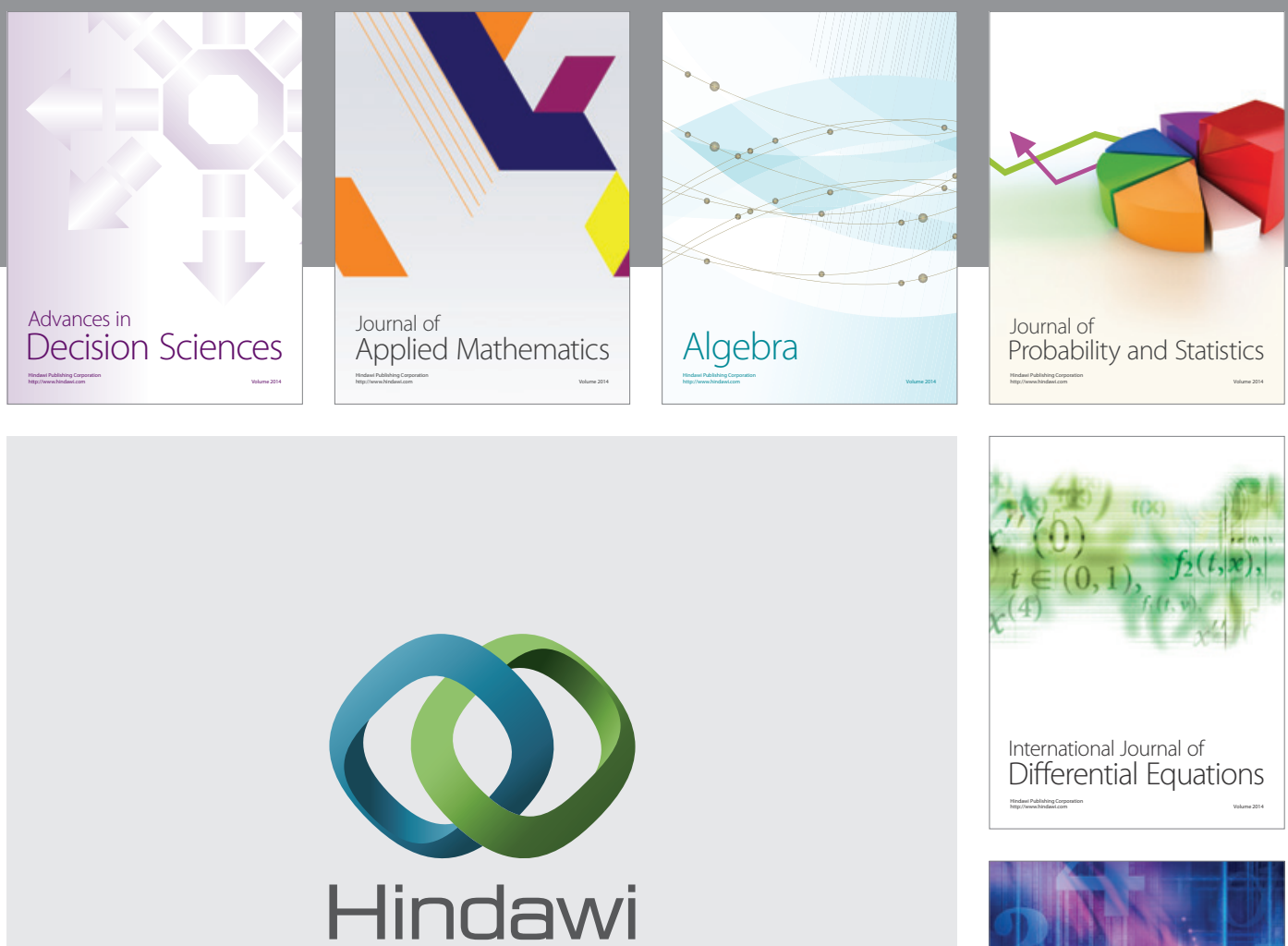

Submit your manuscripts at http://www.hindawi.com
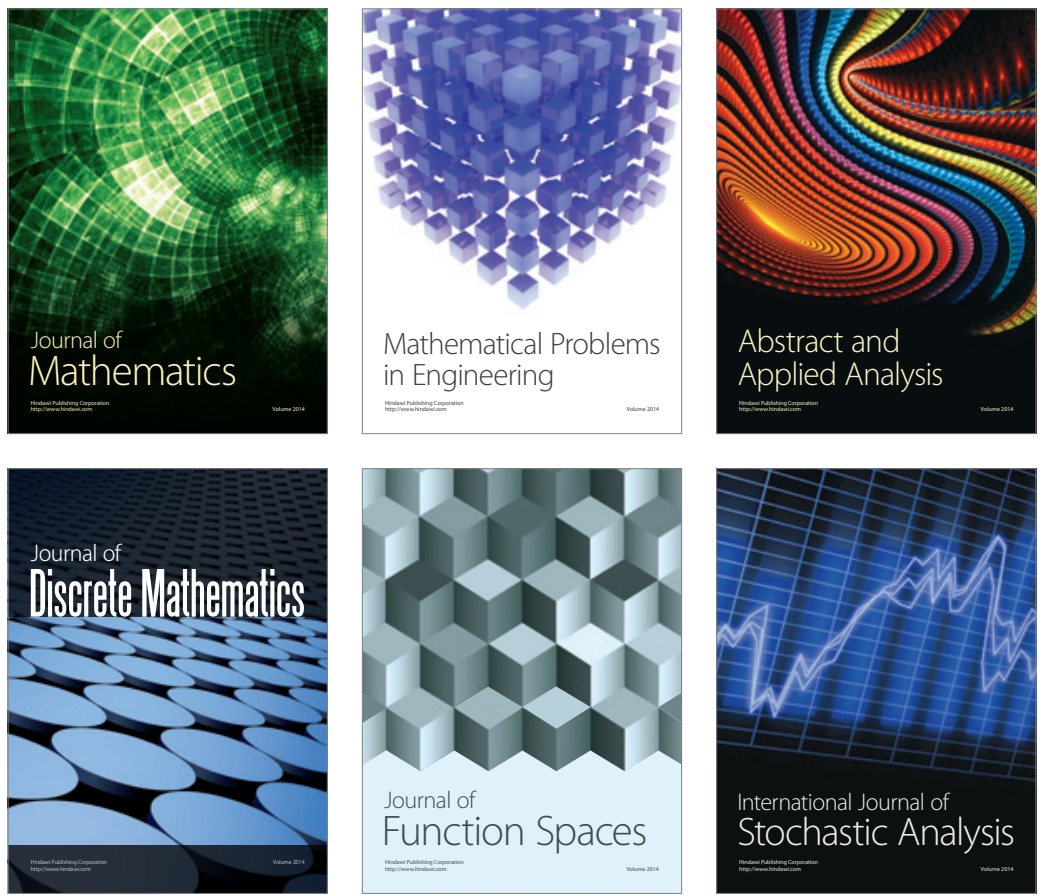

Journal of

Function Spaces

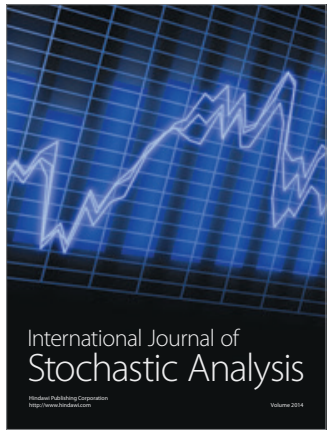

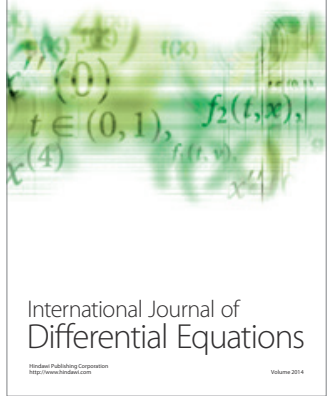
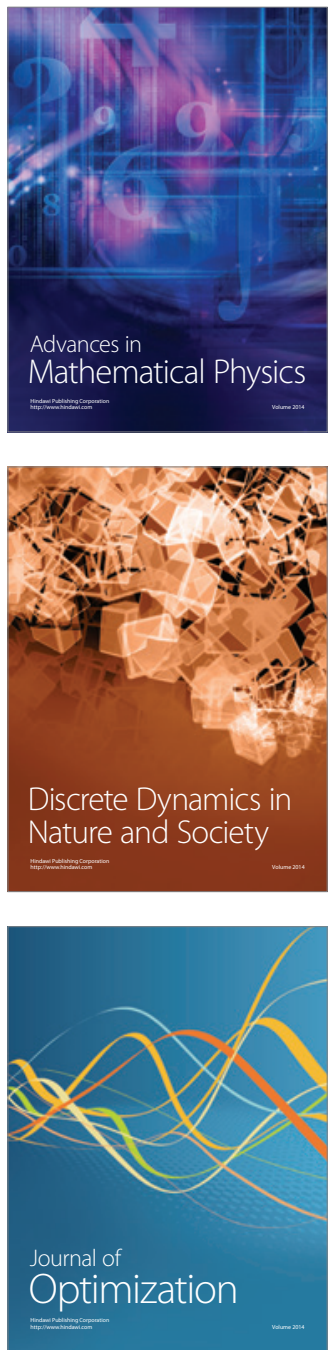